\title{
Phylloquinone and Vitamin D Status: Associations with Incident Chronic Kidney Disease in the Framingham Offspring Cohort
}

\author{
Conall M. O'Seaghdha ${ }^{a, b}$ Shih-Jen Hwang ${ }^{a}$ Rachel Holden ${ }^{\mathrm{e}}$ Sarah L. Booth ${ }^{d}$ \\ Caroline S. Fox ${ }^{\mathrm{a}, \mathrm{c}}$ \\ ${ }^{a}$ National Heart, Lung and Blood Institute's Framingham Heart Study and the Center for Population Studies, \\ Framingham, Mass., ${ }^{b}$ Renal Division and ${ }^{\mathrm{C}}$ Division of Endocrinology, Brigham and Women's Hospital and \\ Harvard Medical School, and d Jean Mayer US Department of Agriculture Human Nutrition Research Center of Aging

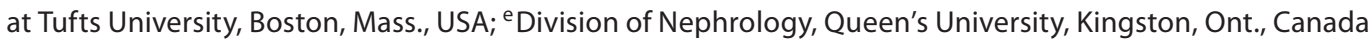

\section{Key Words}

Chronic kidney disease $\cdot$ Vitamin $\mathrm{K} \cdot$ Vitamin D

\begin{abstract}
Background: Cardiovascular risk factors are associated with the development of chronic kidney disease (CKD), and CKD and vascular disease are etiologically linked. Evidence suggests deficiencies of vitamins $\mathrm{D}$ and $\mathrm{K}$ may adversely affect the cardiovascular system, but data from longitudinal studies are lacking. We hypothesized that deficiencies of vitamins $\mathrm{D}$ and $\mathrm{K}$ may be associated with incident CKD and/or incident albuminuria amongst members of the general population. Methods: We analyzed 1,442 Framingham Heart Study participants (mean age 58 years; $50.5 \%$ women), free of CKD (eGFR $<60 \mathrm{ml} / \mathrm{min} / 1.73 \mathrm{~m}^{2}$ ), with a mean follow-up of 7.8 years in 2005-2008. Incident albuminuria was defined using sex-specific cut-offs of urine albumin-to-creatinine ratio ( $\geq 17 \mathrm{mg} / \mathrm{g}$ men and $\geq 25 \mathrm{mg} / \mathrm{g}$ women). Baseline log plasma phylloquinone (vitamin $\mathrm{K}_{1}$ ) and $25(\mathrm{OH}) \mathrm{D}$ levels, analyzed as continuous variables and by quartile, were related to risk of incident CKD $(n=108)$ and incident albuminuria ( $n=106)$ using logistic regression models adjusted for standard risk factors. Results: Participants in the highest phylloquinone quartile ( $\geq 1.78 \mathrm{nmol} / \mathrm{l}$ ) had an increased risk of CKD
\end{abstract}

(multivariable-adjusted $O R Q_{4}$ vs. $Q_{1} 2.39 ; p=0.006$ ) and albuminuria at follow-up (multivariable-adjusted OR $\mathrm{Q}_{4}$ vs. $\mathrm{Q}_{1}$ 1.95; $p=0.05$ ), whereas no association was observed with continuous phylloquinone levels for either endpoint. Deficiency of 25(OH)D was not associated with incident CKD or albuminuria in either analysis. Conclusions: Contrary to our hypothesis, higher plasma phylloquinone levels are associated with an increased risk of incident CKD. Whether plasma phylloquinone is a marker for another unmeasured risk factor requires further study. External validation is necessary given the unexpected nature of these results.

Copyright $\odot 2012$ S. Karger AG, Basel

\section{Introduction}

Chronic kidney disease (CKD) is associated with cardiovascular disease, such that they commonly coexist and the overlap in their etiologies is considerable [1]. However, vascular calcification is more commonly a feature of cardiovascular disease in CKD patients than is observed in the general population [2]. For example, at the time of initiating renal replacement therapy, the majority of end-stage renal disease patients exhibit extensive arterial calcification, typically involving the coronary ar-

\section{KARGER}

Fax +41613061234

E-Mail karger@karger.ch

www.karger.com (c) 2012 S. Karger AG, Basel

0250-8095/12/0361-0068\$38.00/0

Accessible online at:

www.karger.com/ajn
Caroline S. Fox, MD, MPH

National Heart, Lung and Blood Institute's Framingham Heart Study

$73 \mathrm{Mt}$. Wayte Avenue, Suite \#2

Framingham, MA 01702 (USA)

Tel. +1 508935 3447, E-Mail foxca @ nhlbi.nih.gov 
teries, aorta and cardiac valves [3], and the presence and extent of such advanced vascular calcification predicts cardiovascular disease and mortality beyond conventional risk factors $[4,5]$. Advances in imaging techniques have permitted the identification of vascular calcification at earlier stages of CKD in humans [6], while data from animal studies indicates the processes that lead to vascular calcification begin with very mild degrees of renal injury, before the altered mineral metabolism of secondary hyperparathyroidism develops [7].

Deficiencies of vitamins $\mathrm{K}$ and $\mathrm{D}$ are commonly observed across the spectrum of kidney disease stages [8]. Both are fat-soluble nutrients essential to bone health [9, 10], and deficiencies have been linked to vascular calcification in animals [11-13], members of the general population $[14,15]$ and people with kidney disease $[6,12]$. Vitamin K administration causes regression of warfarininduced medial elastocalcinosis in rats [16]. In the case of vitamin $D$, supplementation has been shown to prevent the development of albuminuria in an animal model of diabetic nephropathy [17, 18]. Furthermore, evidence from a recent randomized controlled trial indicates that treatment with the vitamin $\mathrm{D}$ agonist, paricalcitol, reduces proteinuria in established diabetic nephropathy [19].

In light of these observations, we hypothesized that deficiencies of vitamins $\mathrm{D}$ and $\mathrm{K}$ may be associated with incident kidney disease. Using data from the Framingham Offspring cohort, we tested this hypothesis by relating measures of vitamin $\mathrm{K}$ status (as measured by plasma phylloquinone level (vitamin $\mathrm{K}_{1}$ )) and vitamin $\mathrm{D}$ status (plasma 25(OH)D) to risk of incident CKD and incident albuminuria at 8 years' follow-up in a community-based sample of men and women.

\section{Methods}

\section{Study Sample}

Participants were drawn from the Framingham Offspring Study cohort [20]. Offspring participants underwent assessment in 4- to 8-year cycles, which included physical examination, blood biochemistries, assessment of cardiovascular risk factors and physician interview. Samples for vitamins K and D were collected between 1997 and 1999 [the end of examination cycle 6 (1995$1998)$ and the beginning of cycle 7 (1998-2001)]. In total, 1,599 participants had baseline phylloquinone levels drawn and followup creatinine measures available. Of these, 147 were excluded due to baseline CKD, and 10 due to missing covariates, resulting in a final study sample of 1,442 . For the $25(\mathrm{OH}) \mathrm{D}$ analysis, the total sample size was 1,438. All participants provided written informed consent, and the institutional review boards of the Boston University Medical Center approved the study.

Vitamins $\mathrm{K}$ and $\mathrm{D}$ and Incident CKD
Exposure Measurement: Vitamins K and D

Fasting morning blood samples were drawn and plasma was stored at $-80^{\circ} \mathrm{C}$ until processing. Vitamin $\mathrm{K}$ status was assessed by plasma phylloquinone level, as measured by high-pressure liquid chromatography [21]. Low and high control specimens had average values of 0.56 and $3.15 \mathrm{nmol} / \mathrm{l}$, with coefficients of variation (total CVs) of 15.2 and $10.9 \%$, respectively. 25(OH)D status was estimated by measuring plasma $25(\mathrm{OH}) \mathrm{D}$ level using radioimmunoassay (http://www.diasorin.com).

Primary Outcome Assessment: eGFR and Incident CKD

The primary outcome was development of incident CKD, defined as eGFR $<60 \mathrm{ml} / \mathrm{min} / 1.73 \mathrm{~m}^{2}$ using the Modification of Diet in Renal Disease (MDRD) equation [22], by the eighth examination cycle (2005-2008). Serum creatinine levels were measured using the modified Jaffé method. Calibration of serum creatinine values to the Cleveland Clinic Laboratory standard was performed using the correction factor of $0.23 \mathrm{mg} / \mathrm{dl}(20.33 \mu \mathrm{mol} / \mathrm{l})$ [23]. We utilized an alternate definition of incident CKD as a secondary outcome, CKDi25: eGFR $<60 \mathrm{ml} / \mathrm{min}$ at follow-up and at least $25 \%$ decline in eGFR from baseline.

\section{Secondary Outcome Assessment: Incident Albuminuria}

Incident albuminuria was defined using the sex-specific cutoffs of urine albumin-to-creatinine ratio (UACR) $\geq 17 \mathrm{mg} / \mathrm{g}$ in men and $\geq 25 \mathrm{mg} / \mathrm{g}$ in women [24]. UACR was measured on spot morning urine samples collected between 1995 and 1998. After collection, urine samples were stored at $-20^{\circ} \mathrm{C}$ and then transitioned to $-80^{\circ} \mathrm{C}$ until quantification in October 1998 in Children's Hospital, Boston, Mass., USA. Urinary albumin concentration was measured using immunoturbidimetry (Tina-quant Albumin assay; Roche Diagnostics; http://www.roche-diagnostics. us/) and urinary creatinine levels were measured using the Jaffé method; [25] the intra-assay coefficient of variation varied from 1.7 to $3.8 \%$.

\section{Covariate Assessment}

Participants underwent blood testing and were assessed for CKD risk factors. High-density lipoprotein cholesterol (HDL-C) and blood glucose were measured on fasting morning blood samples. Diabetes was defined as fasting blood glucose of $126 \mathrm{mg} / \mathrm{dl}$ ( $7 \mathrm{mmol} / \mathrm{l}$ ) or greater or use of diabetic medication. Systolic and diastolic blood pressure measurements were taken as the mean of two physician readings using a mercury sphygmomanometer. Hypertension was defined as a systolic BP $\geq 140 \mathrm{~mm} \mathrm{Hg}$ or a diastolic BP $\geq 90 \mathrm{~mm} \mathrm{Hg}$ or self-reported use of antihypertensive medications. Body mass index (BMI) was defined as an individual's weight in kilograms divided by height in meters squared. Current smoking status was defined by self-report. Season was also included as a covariate due to seasonal influences on vitamins D status [26]. Season was defined as: June-August, summer; September-November, fall; December-February, winter; MarchMay, spring - with fall, winter and spring being entered as dichotomous variables and summer as the reference.

\section{Statistical Analyses}

Phylloquinone was log-transformed to approximate normality due to a skewed distribution (skewness 7.4). Following log transformation the distribution skewness improved to -0.3 and kurtosis was 1.06. Baseline characteristics of study participants 
were calculated by quartile (Q) of phylloquinone level and the statistical significance of differences was compared using $\chi^{2}$ tests for categorical variables and one-way ANOVA for continuous variables. Pearson's correlation coefficients were used to assess associations between plasma phylloquinone level with age, BMI, systolic blood pressure, HDL-C, log triglycerides, eGFR, UACR and $25(\mathrm{OH}) \mathrm{D}$.

Baseline phylloquinone level was considered both in quartiles and as a continuous variable (per 1 standard deviation (SD) increase). The association between phylloquinone quartile and risk of incident CKD was tested using logistic regression models. Three sets of regression models were constructed: (1) adjusting for age and sex, (2) a multivariable model adjusting for age, sex, diabetes, systolic blood pressure, hypertension treatment, HDL-C, BMI, current smoking and eGFR, and (3) additional adjustment to model 2 for the proportion of circulating undercarboxylated osteocalcin (\%ucOC), a sensitive measure of vitamin $\mathrm{K}$ status. In these regression models, the reference category was $\mathrm{Q}_{1}$ (lowest phylloquinone level).

$25(\mathrm{OH}) \mathrm{D}$ was also analyzed as both a continuous variable and by quartiles, and related to risk of incident CKD and albuminuria using logistic regression models. Participants in the lowest quartile plasma $25(\mathrm{OH}) \mathrm{D}$ levels were used as the reference group. Identical regression models were used as for the phylloquinone analysis. All analyses were performed using SAS, version 9.1 (SAS Institute, Cary, N.C., USA).

\section{Secondary Analyses}

We examined incident albuminuria as a secondary outcome, defined using the sex-specific cut-points of UACR $\geq 17 \mathrm{mg} / \mathrm{g}$ (men) or $\geq 25 \mathrm{mg} / \mathrm{g}$ (women) [27]. As for the CKD analysis, the association between vitamin quartile and risk of albuminuria was tested using two sets of logistic regression models: (1) age- and sex-adjusted, and (2) a multivariable model adjusted for age, sex, diabetes, HDL-C, log triglycerides, current smoking, eGFR and baseline log UACR.

As an additional secondary analysis, we also adjusted for dietary phylloquinone intake, assessed by food frequency questionnaire, in the multivariable model for incident CKD.

\section{Results}

\section{Baseline Characteristics}

Baseline characteristics of the cohort, by quartile of baseline plasma phylloquinone level, are presented in table 1a. Participants with higher phylloquinone levels at baseline were more likely to be men and have hypertension but less likely to smoke tobacco. There were no significant differences in baseline eGFR or albuminuria across quartiles. Data by quartile of baseline plasma 25(OH)D are shown in table $1 b$.

Age- and sex-adjusted cross-sectional correlations of log plasma phylloquinone and plasma $25(\mathrm{OH}) \mathrm{D}$ with established CKD risk factors are presented in table 2. log plasma phylloquinone was correlated with log plasma tri- glyceride level $(r=0.20 ; p<0.0001)$, and inversely correlated with plasma HDL-C $(\mathrm{r}=-0.11 ; \mathrm{p}<0.0001)$. Plasma $25(\mathrm{OH}) \mathrm{D}$ was inversely correlated with $\mathrm{BMI}(\mathrm{r}=-0.22$; $p<0.0001)$. Weaker correlations were observed between plasma $25(\mathrm{OH}) \mathrm{D}$ and log plasma triglyceride level $(\mathrm{r}=$ $-0.09 ; \mathrm{p}=0.0002)$, plasma HDL-C $(\mathrm{r}=0.13 ; \mathrm{p}<0.0001)$ and systolic blood pressure $(r=-0.06 ; \mathrm{p}=0.02)$.

\section{Incident CKD by Vitamin K Status}

Of 1,442 study participants, 108 (7.5\%) developed incident CKD over a mean of 7.8 years' follow-up. In an analysis by baseline phylloquinone quartile, participants in $\mathrm{Q}_{4}(\geq 1.78 \mathrm{nmol} / \mathrm{l}$; highest plasma phylloquinone level) demonstrated an increased risk of incident CKD when compared with $\mathrm{Q}_{1}(\leq 0.55 \mathrm{nmol} / \mathrm{l}$; lowest) in age- and sexadjusted (OR 2.20; 95\% confidence interval (CI) 1.20 $4.00 ; \mathrm{p}=0.01)$ and multivariable-adjusted models (OR 2.39 (1.28-4.46); $\mathrm{p}=0.006$; table 3$)$. The inclusion of \%ucOC in the multivariable incident CKD logistic regression model did not materially alter the results, and \%ucOC was not associated with incident CKD $(\mathrm{p}=0.2)$.

When analyzed as a continuous variable, plasma phylloquinone was not associated with incident CKD (multivariable-adjusted OR per SD increase in plasma phylloquinone: $0.99(0.83-1.19) ; \mathrm{p}=1.0$; table 3$)$. There was no evidence of effect modification by sex ( $\mathrm{p}$ value range for sex-interaction terms: 0.5-1.0).

\section{Incident $\mathrm{CKD}$ by $25(\mathrm{OH}) \mathrm{D}$ Status}

Of 1,438 study participants for the $25(\mathrm{OH}) \mathrm{D}$ analysis, 108 (7.5\%) developed incident CKD over the study period. When analyzed by baseline quartile of $25(\mathrm{OH}) \mathrm{D}$ level, no association with risk of CKD was observed for any quartile compared to the referent in age- and sex-adjusted (for example, $O \mathrm{OR}_{4}$ vs. $\left.\mathrm{Q}_{1}: 1.30(0.74-2.27) ; \mathrm{p}=0.4\right)$ and multivariable-adjusted models (OR $1.44(0.79-2.61) ; \mathrm{p}=0.2$; table 4$)$. When analyzed as a continuous variable, plasma $25(\mathrm{OH}) \mathrm{D}$ was not associated with incident CKD in either age- and sex-adjusted or multivariable-adjusted models (multivariable-adjusted OR per SD increase in plasma 25(OH)D level: $0.85(0.69-1.04) ; \mathrm{p}=0.1$, table 4$)$. There was no evidence of effect modification by sex ( $\mathrm{p}$ value for sex-interaction terms ranges from 0.4 to 0.9 ).

\section{Secondary Analyses}

\section{Alternate Definition of CKD}

Applying a more stringent alternate definition of CKD (follow-up eGFR $<60 \mathrm{ml} / \mathrm{min}$ and at least $25 \%$ decline in eGFR from baseline) yielded fewer cases than the primary analysis $(\mathrm{n}=62 ; 4.3 \%)$. However, results were similar 
Table 1. Baseline characteristics of study participants by quartile of $\mathbf{a}$ plasma phylloquinone (vitamin $\mathrm{K}_{1}$ ) level, $\mathrm{nmol} / \mathrm{l}$, and $\mathbf{b}$ plasma $25(\mathrm{OH}) \mathrm{D}$ level, $\mathrm{ng} / \mathrm{ml}$ (data presented as mean with SD in parentheses for continuous variables or percent with number in parentheses for categorical data)

a

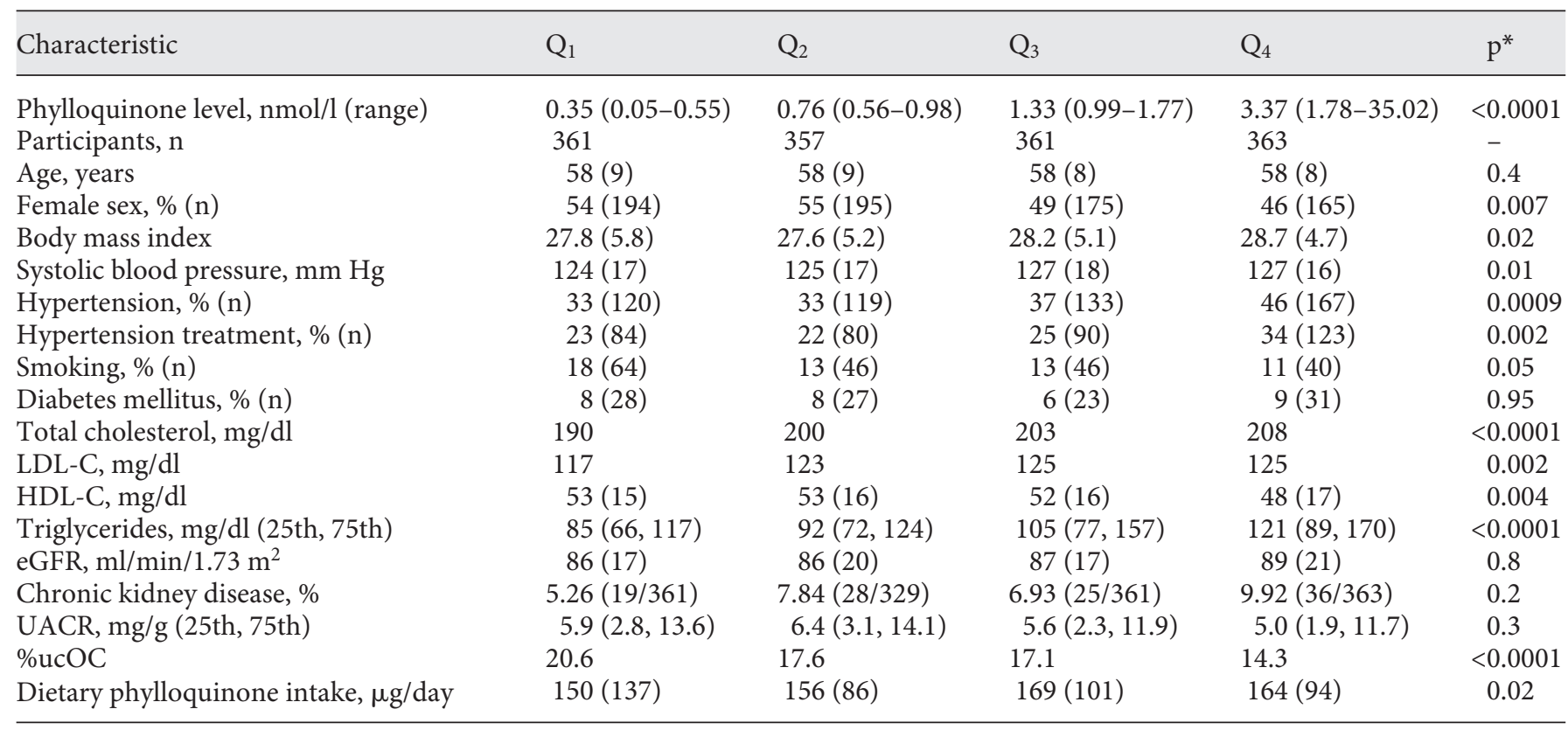

b

\begin{tabular}{|c|c|c|c|c|c|}
\hline Plasma 25(OH) D, ng/ml & $2.2-14.6$ & $14.7-19.1$ & $19.2-24.0$ & $24.1-58.5$ & - \\
\hline Age, years & $58(9)$ & $58(9)$ & $58(9)$ & $58(8)$ & 0.4 \\
\hline Female sex, \% (n) & $49(176)$ & $47(166)$ & $51(186)$ & $56(200)$ & 0.03 \\
\hline Season of blood draw & - & - & - & - & - \\
\hline Fall, \% (n) & $16(58)$ & $32(113)$ & $37(136)$ & $37(135)$ & $<0.0001$ \\
\hline Winter, \% (n) & $43(152)$ & $36(127)$ & $25(91)$ & $19(68)$ & $<0.0001$ \\
\hline Body mass index & $29.6(6.1)$ & $28.8(5.5)$ & $27.3(4.4)$ & $26.6(4.1)$ & $<0.0001$ \\
\hline Systolic blood pressure, $\mathrm{mm} \mathrm{Hg}$ & $128(17)$ & $126(16)$ & $124(17)$ & $125(18)$ & 0.008 \\
\hline Hypertension, \% (n) & $54(193)$ & $53(187)$ & $46(169)$ & $50(178)$ & 0.07 \\
\hline Hypertension treatment, \% (n) & $28(100)$ & $26(92)$ & $27(98)$ & $24(87)$ & 0.4 \\
\hline $\mathrm{eGFR}, \mathrm{ml} / \mathrm{min} / 1.73 \mathrm{~m}^{2}$ & $89(18)$ & $89(20)$ & $87(19)$ & $84(17)$ & 0.3 \\
\hline UACR mg/g (25th, 75th) & $4.6(2.0,9.3)$ & $4.7(1.9,7.8)$ & $4.8(1.8,8.6)$ & $5.0(2.6,9.8)$ & 0.9 \\
\hline
\end{tabular}

HDL = High-density lipoprotein; LDL = low-density lipoprotein; eGFR = estimated glomerular filtration rate; UACR = urine albumin:creatinine ratio; \%ucOC = proportion of circulating undercarboxylated osteocalcin.

* p values are for significance of trend across quartiles, adjusted for age and sex (except age, which is sex-adjusted and sex, which is age-adjusted). Mean phylloquinone level: $1.46 \mathrm{nmol} / \mathrm{l}$.
** $\mathrm{p}$ values are for significance of trend across groups, adjusted for age and sex (except age, which is sex-adjusted and sex, which is age-adjusted). Mean 25(OH)D level: $19.7 \mathrm{ng} / \mathrm{ml}$. 
Table 2. Age- and sex-adjusted cross-sectional partial Pearson correlation coefficients of log plasma phylloquinone (vitamin $\mathrm{K}_{1}$ ) and 25(OH)D levels with kidney disease covariates

\begin{tabular}{|c|c|c|c|c|}
\hline & \multicolumn{2}{|c|}{ Phylloquinone (vitamin $\mathrm{K}_{1}$ ) } & \multicolumn{2}{|c|}{$25(\mathrm{OH}) \mathrm{D}$} \\
\hline & $\mathrm{r}$ & $\mathrm{p}$ value & $\mathrm{r}$ & $\mathrm{p}$ value \\
\hline Body mass index & 0.05 & 0.4 & -0.22 & $<0.0001$ \\
\hline Systolic blood pressure & 0.04 & 0.17 & -0.06 & 0.02 \\
\hline High-density lipoprotein cholesterol & -0.11 & $<0.0001$ & 0.13 & $<0.0001$ \\
\hline Estimated glomerular filtration rate & -0.002 & 0.93 & -0.03 & 0.29 \\
\hline Urine albumin:creatinine ratio* & -0.022 & 0.46 & 0.006 & 0.83 \\
\hline log triglycerides & 0.20 & $<0.0001$ & -0.09 & 0.0002 \\
\hline $25(\mathrm{OH}) \mathrm{D}$ & -0.03 & 0.24 & - & - \\
\hline
\end{tabular}

Table 3. Results of logistic regression for quartile and continuous analyses of plasma phylloquinone level and incident kidney disease $\mathrm{e}^{1}$

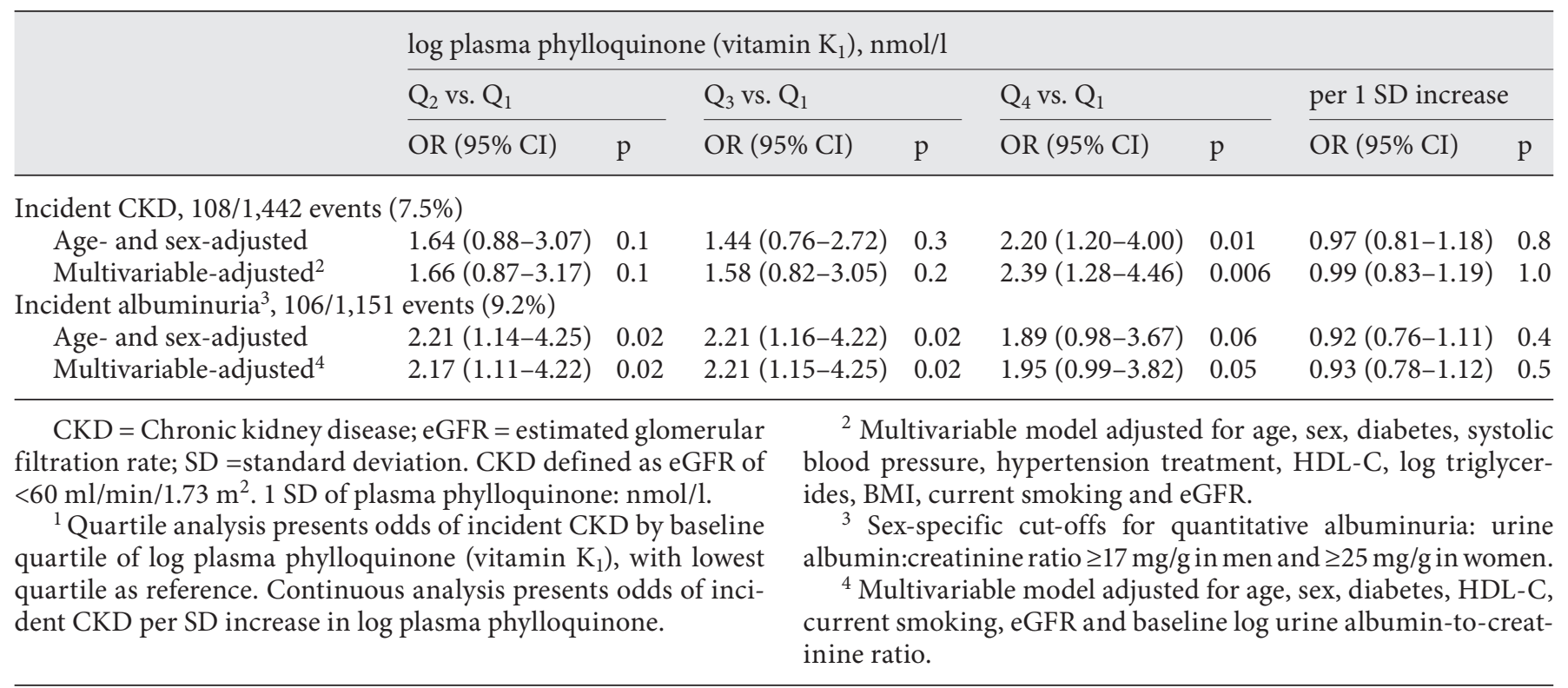

with participants in the highest phylloquinone quartile demonstrating increased risk of CKD at follow-up when compared with the lowest in both models (age- and sexadjusted OR 2.83 (1.32-6.08); $\mathrm{p}=0.008$; multivariableadjusted OR 2.82 (1.28-6.22); $\mathrm{p}=0.01$; data not shown), whereas no association with CKD risk seen in continuous analysis (multivariable-adjusted OR per SD decrease in phylloquinone level 1.01 (0.83-1.23); $\mathrm{p}=0.9$; data not shown).

For $25(\mathrm{OH}) \mathrm{D}$, results were also similar to the primary analysis, with no evidence of association between plasma $25(\mathrm{OH}) \mathrm{D}$ level and CKD risk observed in quartile-based (multivariable-adjusted OR 1.43 (0.69-2.96); $\mathrm{p}=0.3$; data not shown) or continuous analyses (multivariable-adjusted OR per SD decrease in 25(OH)D level 1.10 (0.85-1.41); $\mathrm{p}=0.5$; data not shown).

\section{Incident Albuminuria}

Of 1,151 participants with urinary data available, 106 developed new-onset albuminuria at follow-up (9.2\%). In quartile-based analyses, risk of incident albuminuria was increased in all upper phylloquinone quartiles when compared to lowest (multivariable-adjusted $\mathrm{OR}$ for $\mathrm{Q}_{2} \mathrm{vs}$. $\mathrm{Q}_{1}: 2.17$ (1.11-4.22); $\mathrm{p}=0.02 ; \mathrm{Q}_{3}$ vs. $\mathrm{Q}_{1}: 2.21$ (1.15-4.25); $\mathrm{p}=0.02 ; \mathrm{Q}_{4}$ vs. $\mathrm{Q}_{1}: 1.95$ (0.99-3.82); $\mathrm{p}=0.05$; table 3). There was no association observed between plasma phyl- 
Table 4. Results of logistic regression for quartile and continuous analyses of plasma 25(OH)D level and incident kidney disease ${ }^{1}$

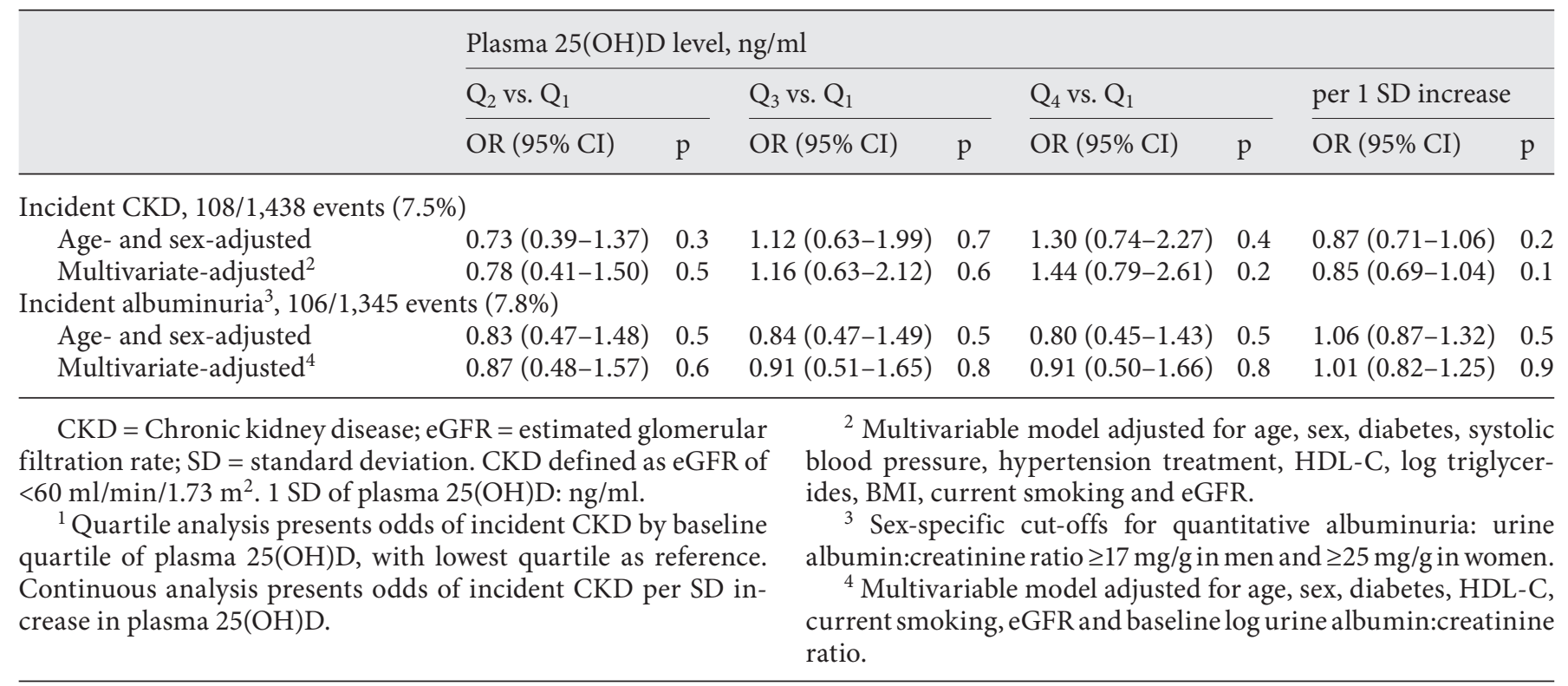

loquinone level analyzed as a continuous variable and incident albuminuria ( $\mathrm{p}=0.5$; table 3$)$. Finally, no association with incident albuminuria was observed in any analysis of $25(\mathrm{OH}) \mathrm{D}$ (multivariable-adjusted OR 0.91 $(0.50-1.66) ; \mathrm{p}=0.8$ for $\mathrm{Q}_{4}$ vs. reference; table 4$)$.

\section{Dietary Phylloquinone Intake}

Of 1,442 participants in the primary analysis, 1,293 had dietary information available. At baseline, there was a trend for greater dietary phylloquinone intake by plasma quartile ( $\mathrm{p}$ for trend 0.02 ; table 1 ). However, additional adjustment for dietary phylloquinone in the multivariable model of incident CKD did not materially affect the results (multivariable-adjusted $\mathrm{OR}$ for $\mathrm{Q}_{2}$ vs. $\mathrm{Q}_{1}$ : OR 1.81 (95\% CI 0.91-3.61, $\mathrm{p}=0.09) ; \mathrm{Q}_{3}$ vs. $\mathrm{Q}_{1}$ : OR 1.87 (95\% CI 0.94-3.71, $\mathrm{p}=0.07) ; \mathrm{Q}_{4}$ vs. $\mathrm{Q}_{1}$ : OR 2.65 (95\% CI 1.37-5.13, $\mathrm{p}=0.004)$.

\section{Discussion}

The findings of our study are twofold. First, contrary to our initial hypothesis, we observed no association between lower circulating phylloquinone levels and any of the three study endpoints, namely incident CKD, incident CKD with evidence of progression, and incident albuminuria. In fact, an unexpected excess risk for these endpoints was detected in the highest phylloquinone quartile. Second, 25(OH)D deficiency was not associated with incident CKD or incident albuminuria.

Vitamin $\mathrm{K}$ is a co-factor in the post-translational $\gamma$ carboxylation of glutamate residues of several vitamin Kdependent proteins, including matrix Gla protein, an inhibitory regulator of tissue mineralization in the arterial wall. Scientific interest in a potential role for vitamin $\mathrm{K}$ in vascular biology and cardiovascular health was stimulated by the demonstration of a lethal phenotype of vascular calcification in the matrix Gla protein knockout mouse [28]. Results from subsequent human studies supported this idea. For example, in a 3-year follow-up study of 388 healthy men and postmenopausal women, phylloquinone $500 \mu \mathrm{g} /$ day conferred a protective effect against progression of vascular calcification, assessed by coronary calcium score, when compared to placebo [29]. Furthermore, a placebo-controlled trial of phylloquinone supplementation in 108 postmenopausal women demonstrated improved vascular compliance, distensibility, and intima media thickness in the treatment arm [30]. Also, plasma phylloquinone levels were inversely associated with circulating inflammatory markers in the Framingham Offspring cohort [31]. In the setting of kidney disease, deficiencies of vitamins $\mathrm{K}$ and $\mathrm{D}$ are prevalent in patients with advanced CKD (stages 3-5) [8]. However it should be noted that these deficiencies appear to be a 
function of an overall decline in nutritional status observed in CKD patients, as sufficiency of both vitamins was predicted by measures of improved nutritional status. In the present study, participants were free of kidney disease at the time of vitamin assay and were a far less sick cohort in general. As such, poor nutrition would not be expected to be a factor.

It is thus unexpected that we observed an increased risk of incident CKD in individuals with higher plasma phylloquinone levels in the present study. There is no tolerable upper intake limit set as there are no known cases of toxicity due to vitamin $\mathrm{K}$ [32]. Unlike other fat-soluble vitamins, vitamin $\mathrm{K}$ is not stored in any significant quantity in the liver, therefore toxic levels are rarely achieved. On the contrary, plasma phylloquinone levels are linearly associated with a 'healthy' dietary intake of green vegetables [33]. Consistent with these observations, adjusting for dietary phylloquinone intake or \%ucOC in the multivariable model did not materially alter the results, and neither variable was associated with incident CKD. These observations suggest the excess risk of kidney disease seen in the highest plasma phylloquinone quartile is not directly mediated by dietary phylloquinone intake or phylloquinone $\gamma$-carboxylase bioactivity.

With no data to support a direct toxic effect of phylloquinone, how might these results be explained? First, this may be an epiphenomenon, and plasma phylloquinone may be a marker of an unmeasured biochemical, genetic or environmental CKD risk factor in our dataset. For example, although variability in biomarkers of vitamin $\mathrm{K}$ status is mostly attributed to non-genetic factors [34], polymorphisms in vitamin K epoxide reductase C1 (VKORC1), for which phylloquinone is a substrate, have been shown to be associated with cross-sectional measures of plasma phylloquinone [35, 36]. VKORC1 haplotypes have also been shown to be associated with vascular calcification in rats [37], accelerated renal allograft loss in humans [38] and aortic calcification in the Rotterdam Study [36]. As such, it is possible that similar polymorphisms in genes involved in phylloquinone metabolism may result in higher plasma phylloquinone levels due to reduced phylloquinone recycling or metabolism, i.e. a functional phylloquinone deficiency state. A similar functional deficiency could result from a variety of factors, such as altered phylloquinone transport, disrupted cellular uptake of phylloquinone or altered conversion of phylloquinone to vitamin $\mathrm{K}_{2}$, and these potential mechanisms are interesting avenues for further study. A second possible explanation for these findings may be that individuals at risk for CKD have a different response to di- etary phylloquinone, which may account for higher circulating levels. Clinical trials of phylloquinone to date have primarily focused on bone disease and have tended to screen out individuals with renal abnormalities. Finally, it is possible that this finding may be a false positive, and external replication of these results is required. However, we observed decreasing \%ucOC with increasing phylloquinone quartiles ( $\mathrm{p}$ for trend $<0.0001$ ), indicative of increasing phylloquinone bioactivity occurring in line with plasma levels, which argues against artifactual phylloquinone elevation in the highest quartile.

The fact that phylloquinone was only associated with CKD risk in the quartile analysis, and not when analyzed as continuous variable, may perhaps be explained by the presence of a 'threshold effect'. Similar threshold relationships have been noted for other biomarkers of incident CKD in the general population, such as plasma phosphorus level [39].

Evidence that $25(\mathrm{OH}) \mathrm{D}$ deficiency plays a role in kidney disease initiation is lacking, although limited animal data suggests it may influence progression of kidney disease. For example, activated vitamin D negatively regulates both the renin-angiotensin system [40] and production of TGF- $\beta_{1}$ [41], a key promoter of renal fibrosis in mice. Furthermore, 25(OH)D may be necessary for maintenance of podocyte structure and prevention of pathologic mesangial cell proliferation in response to renal injury [42]. Studies in humans of $25(\mathrm{OH}) \mathrm{D}$ and progression of kidney disease are scarce, although two small studies suggest a potential benefit of active vitamin D use in slowing the progression of kidney disease $[43,44]$. Furthermore, a recent NHANES III analysis found that participants with $25(\mathrm{OH}) \mathrm{D}$ levels $<15 \mathrm{ng} / \mathrm{ml}$ were more likely to progress to end-stage renal disease compared to those without deficiency [45]. Importantly, the excess risk for developing ESRD was primarily seen in non-Hispanic black individuals in that study. The fact that Framingham participants are white and generally of northern European descent is a critical difference, and may explain the lack of association in the present analysis.

Contrasting with these earlier studies, we did not observe any association with $25(\mathrm{OH}) \mathrm{D}$ deficiency and incident CKD or albuminuria. It should be emphasized that half of the cohort had 25(OH)D levels below current recommended guidelines, hence there was a sufficient distribution with which to identify an effect if it truly existed. Consistent with our null findings, two recent systemic reviews found that the available evidence that vitamin D influences cardiovascular outcomes is incon- 
sistent and contradictory $[46,47]$. Furthermore, a recent Institute of Medicine Committee report concluded that the evidence that vitamin $\mathrm{D}$ supplementation reduces the risk of non-skeletal chronic diseases is inconclusive, fails to establish a cause-and-effect relationship and is insufficient to inform nutritional recommendations [48]. While hypothesis-generating observational and pharmaco-epidemiological studies have stimulated much interest in the potential beneficial effects of vitamin D therapy in CKD amongst other diseases, large randomized controlled trials are now required to test the hypothesis that vitamin $\mathrm{D}$ therapy improves clinical outcomes. The planned NIH-sponsored VITAL study (ClinicalTrials.gov Identifier: NCT01169259) will attempt to clarify the role of vitamin D supplementation for these indications.

Our study has important implications. Existing observational studies that suggest a beneficial effect of phylloquinone on cardiovascular risk generally utilize dietary intake estimates rather than plasma levels [49-51]. These studies may be confounded by phylloquinone intake being primarily a marker of a healthy lifestyle. As the present study indicates potential harm associated with higher plasma phylloquinone, it is essential to validate these findings in independent samples and determine the mechanism of excess CKD risk, which may be independent of dietary intake.

The richness of the dataset with well-defined cardiovascular disease risk factors and long duration of followup considerably strengthens our analysis. However, several limitations must also be acknowledged. First, higher cross-sectional rates of hypertension, use of antihypertensive medications and obesity were present in the highest phylloquinone group. While every effort was made to adjust for these CKD risk factors, the possibility of residual confounding cannot be completely ruled out. Second, CKD was defined using a single creatinine measure, which may have resulted in some misclassification. However, if misclassification occurred, it would be expected to bias our results towards the null and would not account for the positive association with CKD risk seen in the highest phylloquinone quartile. Third, there is no agreed global biomarker of vitamin $\mathrm{K}$ status, and each of the available markers address a different component of absorption, transport and function. For that reason, we chose plasma phylloquinone as a validated biomarker of exposure to vitamin K. Plasma phylloquinone reflects recent dietary intake and supplement use and responds to manipulation of phylloquinone, as validated in controlled human feeding studies [33]. The major limitation of this marker is its fluctuations in response to short-term changes in dietary phylloquinone intake. However, given our large sample size, this variability is likely modest and would be expected to attenuate our findings. Fourth, although the use of a single plasma phylloquinone measure as an indicator of long-term vitamin $\mathrm{K}$ status is imperfect, it is an acceptable measure for ranking participants over a range of levels [33]. Fifth, unlike incident cardiovascular events, the development of CKD is identified through the scheduled examination cycle. Consequently, no exact incident time for CKD can be ascertained and a survivaltype analysis is not possible. Finally, the Framingham Offspring cohort participants are generally older, of northern European descent, and reside in the northeastern United States. As such, our findings should not be generalized to other ethnic/racial groups, younger individuals, or those residing in sunnier climates and have limited use of sunscreen.

Despite these limitations, we have identified that deficiency of vitamins $\mathrm{K}$ or $\mathrm{D}$ is not associated with the development of CKD. Further, an unexplained excess risk of CKD was observed in individuals with the highest plasma phylloquinone levels. Future research should be directed toward replicating these findings in independent samples.

\section{Disclosure Statement}

This material is based upon work supported by the US Department of Agriculture, under agreement No. 58-1950-4-401, the National Institute of Health (AG14759). The Framingham Heart Study is supported by the National Heart, Lung, and Blood Institute (N01-HC-25195). The funding source had no role in the design, conduct, or reporting of the study or in the decision to submit the report for publication. Any opinions, findings, conclusions, or recommendations expressed in this publication are those of the authors and do not necessarily reflect the view of the US Department of Agriculture.

References

1 Ronco C, Haapio M, House AA, Anavekar N, Bellomo R: Cardiorenal syndrome. J Am Coll Cardiol 2008;52:1527-1539.

2 Russo D, Palmiero G, De Blasio AP, Balletta MM, Andreucci VE: Coronary artery calcification in patients with CRF not undergoing dialysis. Am J Kidney Dis 2004;44:10241030.

-3 Hujairi NM, Afzali B, Goldsmith DJ: Cardiac calcification in renal patients: what we do and don't know. Am J Kidney Dis 2004;43: 234-243. 
4 Blacher J, Guerin AP, Pannier B, Marchais SJ, London GM: Arterial calcifications, arterial stiffness, and cardiovascular risk in endstage renal disease. Hypertension 2001;38: 938-942.

5 Blacher J, Guerin AP, Pannier B, Marchais SJ, Safar ME, London GM: Impact of aortic stiffness on survival in end-stage renal disease. Circulation 1999;99:2434-2439.

-6 Garcia-Canton C, Bosch E, Ramirez A, Gonzalez Y, Auyanet I, Guerra R, et al: Vascular calcification and 25-hydroxyvitamin D levels in non-dialysis patients with chronic kidney disease stages 4 and 5. Nephrol Dial Transplant 2011;26:2250-2256.

7 Hruska KA, Mathew S, Davies MR, Lund RJ: Connections between vascular calcification and progression of chronic kidney disease: therapeutic alternatives. Kidney Int Suppl 2005;99:142-151.

8 Holden RM, Morton AR, Garland JS, Pavlov A, Day AG, Booth SL: Vitamins K and D status in stages 3-5 chronic kidney disease. Clin J Am Soc Nephrol 2010;5:590-597.

$\checkmark 9$ Cockayne S, Adamson J, Lanham-New S, Shearer MJ, Gilbody S, Torgerson DJ: Vitamin $\mathrm{K}$ and the prevention of fractures: systematic review and meta-analysis of randomized controlled trials. Arch Intern Med 2006;166:1256-1261.

-10 Wolff AE, Jones AN, Hansen KE: Vitamin D and musculoskeletal health. Nat Clin Pract Rheumatol 2008;4:580-588.

11 Shobeiri N, Adams MA, Holden RM: Vascular calcification in animal models of CKD: a review. Am J Nephrol 2010;31:471-481.

$\checkmark 12$ Krueger T, Westenfeld R, Ketteler M, Schurgers LJ, Floege J: Vitamin K deficiency in CKD patients: a modifiable risk factor for vascular calcification? Kidney Int 2009;76: $18-22$.

13 Zittermann A, Schleithoff SS, Koerfer R: Vitamin D and vascular calcification. Curr Opin Lipidol 2007;18:41-46.

14 Geleijnse JM, Vermeer C, Grobbee DE, Schurgers LJ, Knapen MH, van der Meer IM, et al: Dietary intake of menaquinone is associated with a reduced risk of coronary heart disease: the Rotterdam Study. J Nutr 2004;134:3100-3105.

-15 Young KA, Snell-Bergeon JK, Naik RG, Hokanson JE, Tarullo D, Gottlieb PA, et al: Vitamin $\mathrm{D}$ deficiency and coronary artery calcification in subjects with type 1 diabetes. Diabetes Care 2011;34:454-458.

-16 Schurgers LJ, Spronk HM, Soute BA, Schiffers PM, DeMey JG, Vermeer C: Regression of warfarin-induced medial elastocalcinosis by high intake of vitamin $\mathrm{K}$ in rats. Blood 2007;109:2823-2831.

-17 Deb DK, Sun T, Wong KE, Zhang Z, Ning G, Zhang Y, et al: Combined vitamin D analog and AT1 receptor antagonist synergistically block the development of kidney disease in a model of type 2 diabetes. Kidney Int 2010;77: 1000-1009.
Zhang Y, Deb DK, Kong J, Ning G, Wang Y, Li G, et al: Long-term therapeutic effect of vitamin $\mathrm{D}$ analog doxercalciferol on diabetic nephropathy: strong synergism with AT1 receptor antagonist. Am J Physiol Renal Physiol 2009;297:F791-F801.

19 De Zeeuw D, Agarwal R, Amdahl M, Audhya P, Coyne D, Garimella T, et al: Selective vitamin $\mathrm{D}$ receptor activation with paricalcitol for reduction of albuminuria in patients with type 2 diabetes (VITAL study): a randomised controlled trial. Lancet 2010;376:1543-1551.

20 Kannel WB, Feinleib M, McNamara PM, Garrison RJ, Castelli WP: An investigation of coronary heart disease in families. The Framingham Offspring Study. Am J Epidemiol 1979;110:281-290.

21 Davidson KW, Sadowski JA: Determination of vitamin K compounds in plasma or serum by high-performance liquid chromatography using postcolumn chemical reduction and fluorimetric detection. Methods Enzymol 1997;282:408-421.

22 Levey AS, Bosch JP, Lewis JB, Greene T, Rogers N, Roth D: A more accurate method to estimate glomerular filtration rate from serum creatinine: a new prediction equation. Modification of Diet in Renal Disease Study Group. Ann Intern Med 1999;130:461-470.

23 Coresh J, Astor BC, McQuillan G, Kusek J, Greene T, Van Lente F, et al: Calibration and random variation of the serum creatinine assay as critical elements of using equations to estimate glomerular filtration rate. Am J Kidney Dis 2002;39:920-929.

- 24 Eknoyan G, Hostetter T, Bakris GL, Hebert L, Levey AS, Parving HH, et al: Proteinuria and other markers of chronic kidney disease: a position statement of the National Kidney Foundation (NKF) and the National Institute of Diabetes and Digestive and Kidney Diseases (NIDDK). Am J Kidney Dis 2003; 42:617-622.

25 Hsu CC, Brancati FL, Astor BC, Kao WH, Steffes MW, Folsom AR, et al: Blood pressure, atherosclerosis, and albuminuria in 10,113 participants in the atherosclerosis risk in communities study. J Hypertens 2009;27: 397-409.

-26 Dawson-Hughes B, Harris SS, Dallal GE: Plasma calcidiol, season, and serum parathyroid hormone concentrations in healthy elderly men and women. Am J Clin Nutr 1997;65:67-71.

27 Mattix HJ, Hsu CY, Shaykevich S, Curhan G: Use of the albumin/creatinine ratio to detect microalbuminuria: implications of sex and race. J Am Soc Nephrol 2002;13:1034-1039.

-28 Luo G, Ducy P, McKee MD, Pinero GJ, Loyer E, Behringer RR, et al: Spontaneous calcification of arteries and cartilage in mice lacking matrix GLA protein. Nature 1997;386:78-81.

29 Shea MK, O'Donnell CJ, Hoffmann U, Dallal GE, Dawson-Hughes B, Ordovas JM, et al: Vitamin K supplementation and progression of coronary artery calcium in older men and women. Am J Clin Nutr 2009;89:1799-1807.
30 Braam LA, Hoeks AP, Brouns F, Hamulyak K, Gerichhausen MJ, Vermeer C: Beneficial effects of vitamins $\mathrm{D}$ and $\mathrm{K}$ on the elastic properties of the vessel wall in postmenopausal women: a follow-up study. Thromb Haemost 2004;91:373-380.

31 Shea MK, Booth SL, Massaro JM, Jacques PF, D’Agostino RB Sr, Dawson-Hughes B, et al: Vitamin $\mathrm{K}$ and vitamin $\mathrm{D}$ status: associations with inflammatory markers in the Framingham Offspring Study. Am J Epidemiol 2008;167:313-320.

32 Institute of Medicine 2001: Dietary Reference Intakes for Vitamin A, Vitamin K, Arsenic Boron, Chromium, Copper, Iodine, Iron, Manganese, Molybdenum, Nickel, Silicon, Vanadium, and Zinc. Washington, National Academy Press, 2001.

33 McKeown NM, Jacques PF, Gundberg CM, Peterson JW, Tucker KL, Kiel DP, et al: Dietary and nondietary determinants of vitamin $\mathrm{K}$ biochemical measures in men and women. J Nutr 2002;132:1329-1334.

- 34 Shea MK, Benjamin EJ, Dupuis J, Massaro JM, Jacques PF, D'Agostino RB Sr, et al: Genetic and non-genetic correlates of vitamins K and D. Eur J Clin Nutr 2009;63:458-464.

35 Crosier MD, Peter I, Booth SL, Bennett G, Dawson-Hughes B, Ordovas JM: Association of sequence variations in vitamin $\mathrm{K}$ epoxide reductase and $\gamma$-glutamyl carboxylase genes with biochemical measures of vitamin K status. J Nutr Sci Vitaminol (Tokyo) 2009;55: 112-119.

-36 Teichert M, Visser LE, van Schaik RH, Hofman A, Uitterlinden AG, De Smet PA, et al: Vitamin K epoxide reductase complex subunit 1 (VKORC1) polymorphism and aortic calcification: the Rotterdam Study. Arterioscler Thromb Vasc Biol 2008;28:771-776.

37 Kohn MH, Price RE, Pelz HJ: A cardiovascular phenotype in warfarin-resistant VKORC1 mutant rats. Artery Res 2008;2:138-147.

38 Quteineh L, Verstuyft C, Durrbach A, Letierce A, Ferlicot S, Charpentier B, et al: Impact of VKORC1 haplotypes on long-term graft function in kidney transplantation. Transplantation 2008;86:779-783.

39 O'Seaghdha CM, Hwang SJ, Muntner P, Melamed ML, Fox CS: Serum phosphorus predicts incident chronic kidney disease and end-stage renal disease. Nephrology, dialysis, transplantation: official publication of the European Dialysis and Transplant Association - European Renal Association 2011; 26:2885-2890.

40 Li YC, Kong J, Wei M, Chen ZF, Liu SQ, Cao LP: 1,25-Dihydroxyvitamin $\mathrm{D}_{3}$ is a negative endocrine regulator of the renin-angiotensin system. J Clin Invest 2002;110:229-238.

41 Makibayashi K, Tatematsu M, Hirata M, Fukushima N, Kusano K, Ohashi S, et al: A vitamin $\mathrm{D}$ analog ameliorates glomerular injury on rat glomerulonephritis. Am J Pathol 2001;158:1733-1741. 
42 Migliori M, Giovannini L, Panichi V, Filippi C, Taccola D, Origlia N, et al: Treatment with 1,25-dihydroxyvitamin $\mathrm{D}_{3}$ preserves glomerular slit diaphragm-associated protein expression in experimental glomerulonephritis. Int J Immunopathol Pharmacol 2005; 18:779-790.

43 Chan JC, Kodroff MB, Landwehr DM: Effects of 1,25-dihydroxyvitamin- $\mathrm{D}_{3}$ on renal function, mineral balance, and growth in children with severe chronic renal failure. Pediatrics 1981;68:559-571.

44 Coen G, Mazzaferro S, Manni M, Fondi G, Perruzza I, Pasquali M, et al: No acceleration and possibly slower progression of renal failure during calcitriol treatment in predialysis chronic renal failure. Nephrol Dial Transplant 1994;9:1520.
-45 Melamed ML, Astor B, Michos ED, Hostetter TH, Powe NR, Muntner P: 25-Hydroxyvitamin D levels, race, and the progression of kidney disease. J Am Soc Nephrol 2009;20: 2631-2639.

46 Pittas AG, Chung M, Trikalinos T, Mitri J, Brendel M, Patel K, et al: Systematic review: vitamin $\mathrm{D}$ and cardiometabolic outcomes. Ann Intern Med 2010;152:307-314.

47 Wang L, Manson JE, Song Y, Sesso HD: Systematic review: vitamin D and calcium supplementation in prevention of cardiovascular events. Ann Intern Med 2010;152:315323.
48 Institute of Medicine 2011: Dietary Reference Intakes for Calcium and Vitamin D. Washington, National Academy Press, 2010.

49 Erkkila AT, Booth SL, Hu FB, Jacques PF, Lichtenstein AH: Phylloquinone intake and risk of cardiovascular diseases in men. Nutr Metab Cardiovasc Dis 2007;17:58-62.

50 Erkkila AT, Booth SL, Hu FB, Jacques PF, Manson JE, Rexrode KM, et al: Phylloquinone intake as a marker for coronary heart disease risk but not stroke in women. Eur J Clinical Nutr 2005;59:196-204.

51 Braam L, McKeown N, Jacques P, Lichtenstein A, Vermeer C, Wilson P, et al: Dietary phylloquinone intake as a potential marker for a heart-healthy dietary pattern in the Framingham Offspring cohort. J Am Diet Assoc 2004;104:1410-1414. 